Full-text Available Online at www.bioline.org.br/ja
J. Appl. Sci. Environ. Mgt. June, 2006

Vol. 10 (2) 61 - 66

\title{
Studies on the Intestinal Worm (Helminthiasis) infestation in a Central Nigerian Rural Community
}

\section{${ }^{* 1}$ ANOSIKE, JC; ${ }^{1}$ ZACCHEAUS, VO; ${ }^{1}$ ADEIYONGO, CM; ${ }^{2}$ ABANOBI, OC; ${ }^{1}$ DADA, EO; ${ }^{3} \mathrm{OKU}, \mathrm{EE} ;{ }^{1} \mathrm{KEKE}, \mathrm{IR} ;{ }^{4} \mathrm{UWAEZUOKE}, \mathrm{JC} ;{ }^{4} \mathrm{AMAJUOYI}, \mathrm{OU} ;{ }^{5} \mathrm{OBIUKWU}$, CE; ${ }^{4}$ NWOSU, DC; ${ }^{4}$ OGBUSU, FI}

\author{
${ }^{1}$ Department of Zoology, University of Jos P.M.B. 2084, Jos, Plateau State, Nigeria \\ ${ }^{2}$ Department of Community Medicine, College of Medicine and Health Sciences, Abia State, University, Uturu, Nigeria \\ ${ }^{3}$ Department of Biological Sciences, University of Calabar, Nigeria \\ ${ }^{4}$ Department of Animal \& Environmental Biology, Imo State University, Owerri, Nigeria. \\ ${ }^{5}$ Department of Industrial Microbiology, Imo State University, Owerri, Nigeria. \\ E-mail: jc_anosike@yahoo.Com
}

\begin{abstract}
The prevalence of intestinal helminth of residents of Naraguta rural community in Central Nigeria is presented. Out of 700 stool specimens examined between January and July 1999, 261 (37.3\%) were positive for helminthic infections. Helminths encountered include Hookworm, Schistosoma mansoni, Trichuris trichiura, Strongyloides stercoralis, Ascaris lumbricoides, and Hymenolepis nana. Hookworm was the most predominant, followed by S. stercoralis, S. mansoni and A. lumbricoides with T. trichiura as the least. Intestinal helminthiasis was equally prevalent for males and females. However, infection rates were high among persons below ten years of age, in toddlers, housewives and farmers than others. Persons defecating in the bush harbored more worms (56.7\%) than pit latrine users (43.3\%). Free medical diagnosis in most rural communities in Nigeria are probably justifiable and should be promoted and/or sustained by government. For protective purposes, conscientious personal cleanliness, proper sanitation and controlled good water supplies would be more useful. @JASEM
\end{abstract}

Infection with parasitic helminths is often recognized as one of the important public health problems in tropical Africa. In a world of 2,200 million inhabitants; there existed over 2,000 million helminth infections with about 15 million Nigerian suffering from ascariasis alone while there are several thousands with strongyloidiasis, trichuriasis, enterobiasis, hookworm, tapeworm infections among others (Edungbola, 1990). This indicates that the prevalence of and morbidity from intestinal helminthiasis is enormous. Many parasitic infections, especially those of helminthic origin are asymptomatic, could produce mild or, in a typical cases, confusing symptoms and are often neglected until bizarre, serious or chronic clinical pictures are present. In most rural communities low standard of sanitation and poor socio-economic conditions are obvious predisposing factors to high prevalence of human intestinal helminthiasis ( Alo et al, 1993, Gundiri and Akogun 2000). Although several reports exist in Nigeria on the mortality and morbidity of most intestinal helminth parasites (Ogbe and Odudu 1990; Dada et al, 1993) the much needed baseline data on the level of endemicity of human intestinal helminthiasis especially on the rural sectors are not easily recorded and do not exist, (Ukoli 1990). Indeed, most reports in Nigeria have been based on parasitological examinations of hospital patients (Kogi et al, 1991, Abdullahi and Abdunlazeez 2000) or urban dwellers and only seldomly did a study involve an entire rural community (Ndifon 1991, Luka et al 2000) where poor sanitation, domestic hygiene, general ignorance of the diseases enhance the problem. This investigation was carried out to assess the status of human intestinal helminthiasis in a rural community located in central Nigeria.

\section{MATERIALS AND METHODS}

Area of Study: The study area is a rural village called Naraguta. The community is situated in the Northern part of Jos North Local Government Area, Central Nigeria. it has an estimated population of about 3,000 people with a diameter of about 9- square kilometers. Naraguta rural community stand on an elevation of $1,000-1,500 \mathrm{~m}$ above sea level with a rather high annual rainfall of $1,600-2,000 \mathrm{~mm}$. The community is a tin mining area hence majority of the villagers like farming, fishing, driving, clay mining and moulding (done mostly by the womenhousewives), leather works (hide and skin) as well as trading.

Sampling techniques and parasitological methods: Prior to the collection of stool specimens from members of selected households from Naraguta community; preliminary work involving a random cluster sampling of households was carried out. As far as possible, every member of the selected households was persuaded to participate. A total of 700 persons selected from persons residing in the village provided 
stool specimens for examination between January and July 1999. A questionnaire was administered to each person from which the sample was collected to obtain personal information data on age, sex, occupation, source of drinking water as well as type of toilet facility used. Specimen bottles were given to the randomly selected persons from various households. They were instructed to provide possibly, "early morning stool" for retrieval the next day. Each participant produced about 10-15gm of stool samples.
The samples were transported to our central laboratory and examined microscopically using the MIFC (mertheolate-iodine-formaldehyde concentration) technique (Ukoli; 1990). Actually, this method has the merit of being efficient and gives higher egg recovery than other methods. More so, depending on the availability of the desired chemicals, we adopted a more accurate method of the KATO think smear technique (Onwuliri et al, 1993).

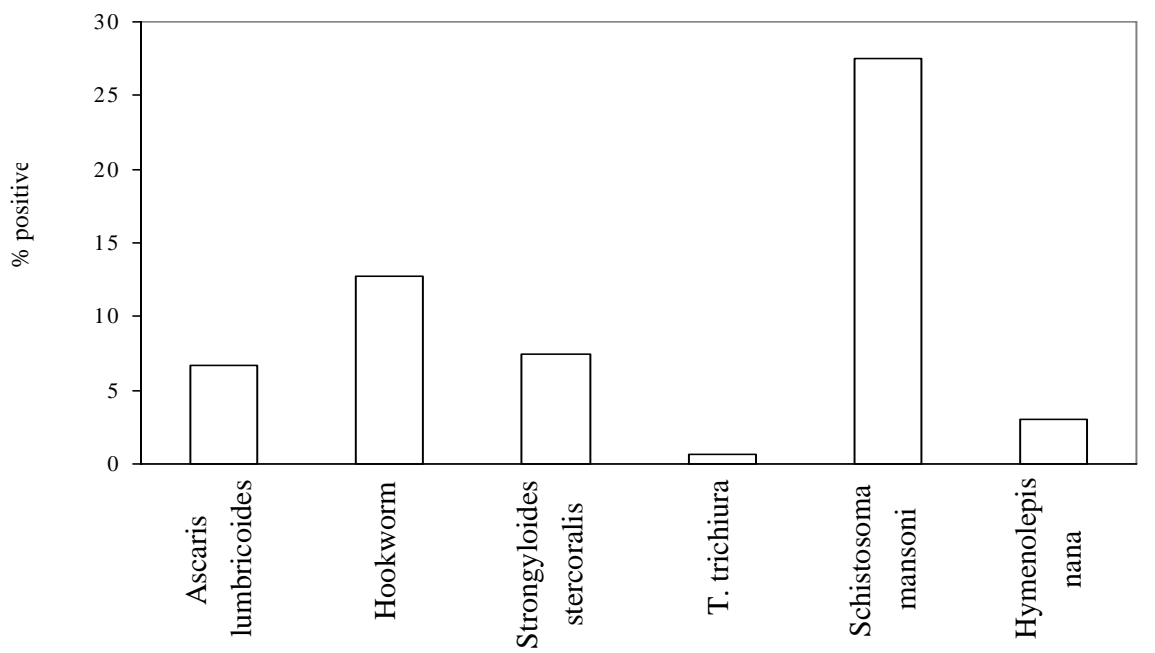

Fig 1: Prevalence of helminth parasites in Naraguta village

\section{RESULTS}

Figure 1 shows the prevalence of helminths in Naraguta village. Generally six types of helminths were encountered: Hookworm, Strongyloides stercoralis, Schistosoma mansoni, Ascaris lumbricoides, Hymenolepis nana and Trichuris trichiura. Of the 700 stool specimens examined, 261 (37.3\%) were positive for helminth infection. Variations were observed in prevalence of each helminth (Chi-square test, $\mathrm{P}<0.05$ ). The prevalence of T. trichiura was significantly lower than other parasites encountered $(\mathrm{P}<0.01)$. Hookworm $(12.7 \%)$ was most predominant followed by $S$. stercoralis (7.4\%), $S$ mansoni (6.7\%) and A. lumbricoides (6.7\%). Figure 2 illustrates the sex-related prevalence of helminth parasites in Naraguta village. Although females generally had higher infection rate (39.3\%) than males (34.5\%), it was not statistically significant (sign test, $\mathrm{P}<0.05$ ). except $T$. trichiura which was absent in males, other parasites were recorded in both sexes. Prevalence of helminth infection in relation to age is shown in table 1 . Children between the age group 6-10 years old had the highest infection rate (51.7\%) of the helminths; with Hookworm showing the highest infection rate (19.2\%) followed by $A$. lumbricoides (12.5\%). Adults in the age group 21-23 years cohort were observed to have the next infection rate $(47.5 \%)$ followed by persons in the age group $26-$ 30 years old $(41.3 \%)$. Least infection rate was observed in people of age group 40 years and above (15.0\%). Analysis of the actual data (using $\mathrm{X}^{2}$ ) showed that there was a significant difference in infection rates among various age groups $(\mathrm{P}<0.05)$. Figure 3 further illustrates this age-related distribution in different parasite types. Furthermore, figure 4 depicts the prevalence of helminth parasites with respect to occupation in Naraguta with toddlers and housewives (designated as others) having the highest infection rate $(51.0 \%)$ followed by farmers $(35.0 \%)$ and pupils (34.0\%). Miners and fishermen had the least infection rate of $18.3 \%$. Similarly, a chi-square analysis showed a significant difference in infection rates among different occupational groups. We also noted that most people in this rural community defecate in the bush while only a few persons use pit latrine. As expected, those who defecated in the bush harbored more nematodes (56.7\%) than pit latrine users (43.3\%). Furthermore, we observed that persons with low level of hygiene had high infection rates too. 


\section{DISCUSSION}

The present investigation on intestinal helminthiasis indicates that hookworms, S. stercoralis, A. lumbricoides as well as $S$. mansoni were more prevalent amongst inhabitants of Naraguta community. These results and those collated by (Ogbe and Odudu, 1990; Ndifon 1991; Kogi et al, 1991; Gundiri and Akogun 2000) show that these parasites, particularly hookworms and Ascaris, are common throughout much of Nigeria. The relatively high prevalence of helminths (37.3\%) observed here agrees with previous findings in parts of Northern Nigeria (Kogi et al, 1991, Alo et al, 1993). Several other reports from other parts of tropical Africa have shown very high $(>70 \%)$ infection rates of intestinal helminths (Dada et al, 1993) Variations in prevalence rate of intestinal helminthiasis from different rural communities could be related to several factors including people's level of education, standard of personal/environmental hygiene and perhaps social habits. More so, some ecological factors such as temperature, relative humidity, rainfall (Onwuliri et $a l, 1993)$, different diagnostic techniques employed by various workers could be responsible for observed differences in prevalence between communities. This calls for a uniform standard diagnostic technique for any National Control program on intestinal helminthiasis.

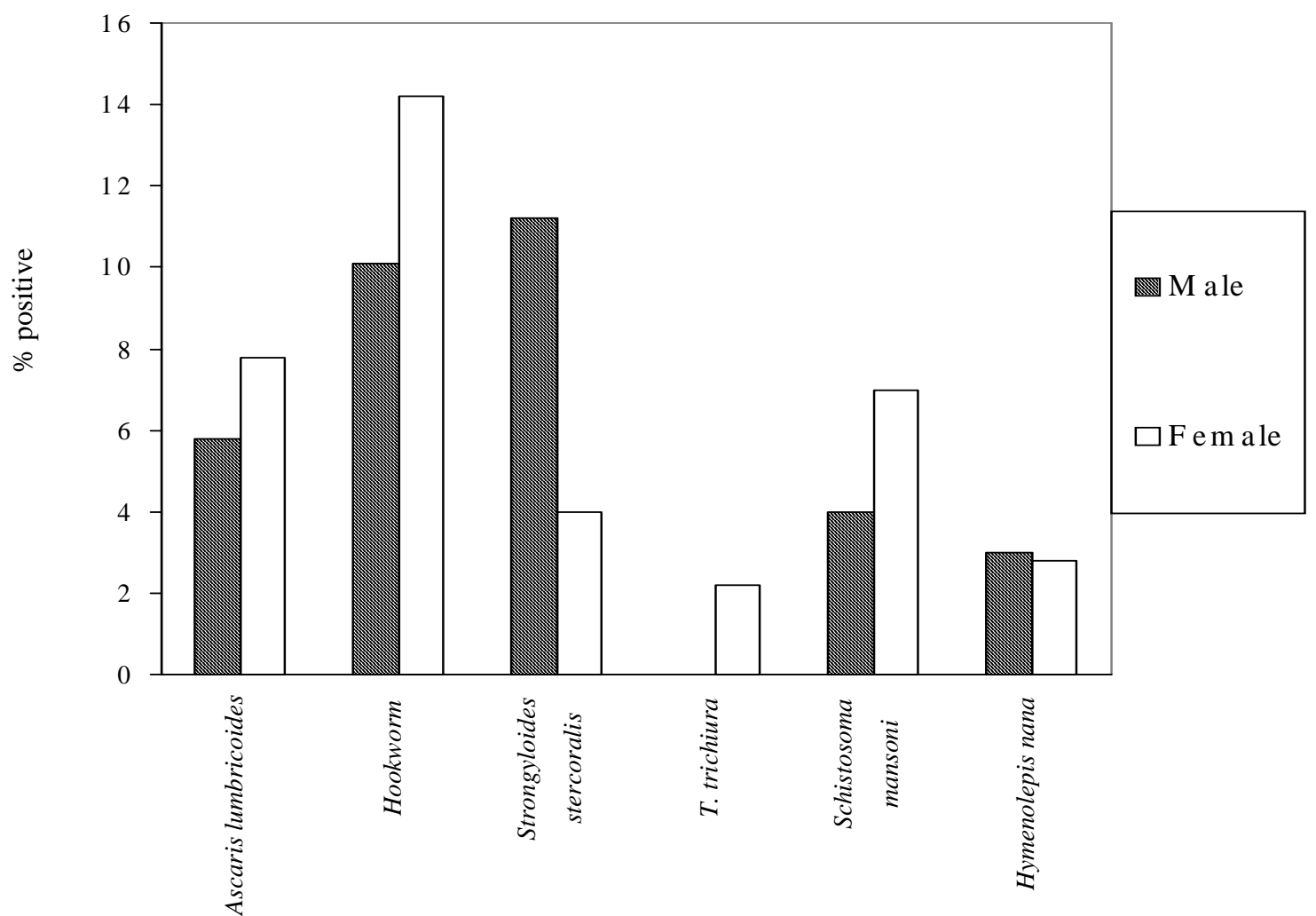

Fig 2: Prevalence of helminth parasites in relation to

Hookworms were the commonest helminths in our study. Although they were not differentiated, other studies have aptly documented the existence of both Necator americanus and Ancylostoma duodenale in the southern parts of Nigeria with the former being more common (Odelowo 1990). Contrary to the report of Kuka et al (2002) who recorded a prevalence rate of $2.1 \%$ for $S$. stercoralis larvae in southwest Nigeria, this parasite was the second commonest helminths in our survey (7.4\%); similar to the report of Alo et al (1993) in Northern Nigeria. This is an indication that infections with S. stercoralis could be of greater importance in both central and Northern parts of Nigeria than in southern Nigeria. Plausibly, this implicates the ecological suitability of local environmental conditions for this helminth in the savannah regions of Nigeria.

A number of gastrointestinal helminths such as Moniliformis moniliformis, Dicrocoelium, Fasciola,

Anosike, JC; Zaccheaus, VO; Adeiyongo, CM; Abanobi, OC; Dada, EO; Oku, EE; Keke, IR; Uwaezuoke, JC; Amajuoyi, OU; Obiukwu, CE; Nwosu, DC; Ogbusu, FI 
Diphyllobothrium, Capillaria or Hepaticola sp. have been found only rarely in parts of Nigeria and elsewhere (Ike et al 1992) but they were not seen in our specimens. As noted by other investigators in Nigeria the males were as exposed to the infective stages of helminths as their female colleagues; they lived in equally The pattern of infection rate observed in the present work is in line with the reports of other researchers (Odelowo 1988-90) where prevalence rates decreases with increase in host age. Infection of children occurs at a very early age even within the first year of life, and is recurrent. Poor sanitary conditions as the men, farm in the same bush area, and even laundered in the same village streams. Toddlers and housewives were mostly affected followed by pupils and miners while fishermen were the least. This could be related to their low level of hygiene and age related high exposure potentials. However, the high occurrence of Trichuris amongst Civil Servants may not have an easy explanation since Trichuris as well as Ascaris species are usually acquired only by ingestion of embryonated eggs. On the other hand, the high prevalence of $H$. nana observed amongst pupils is expected. Other investigators have subscribed to the report that infection with $H$. nana is most frequent in children but occurs in adult (Alo et al 1993; Kuka et al 2002). This is due to the fact that infection is usually transmitted through the ingestion of eggs as a result of faecal contamination of water and food.

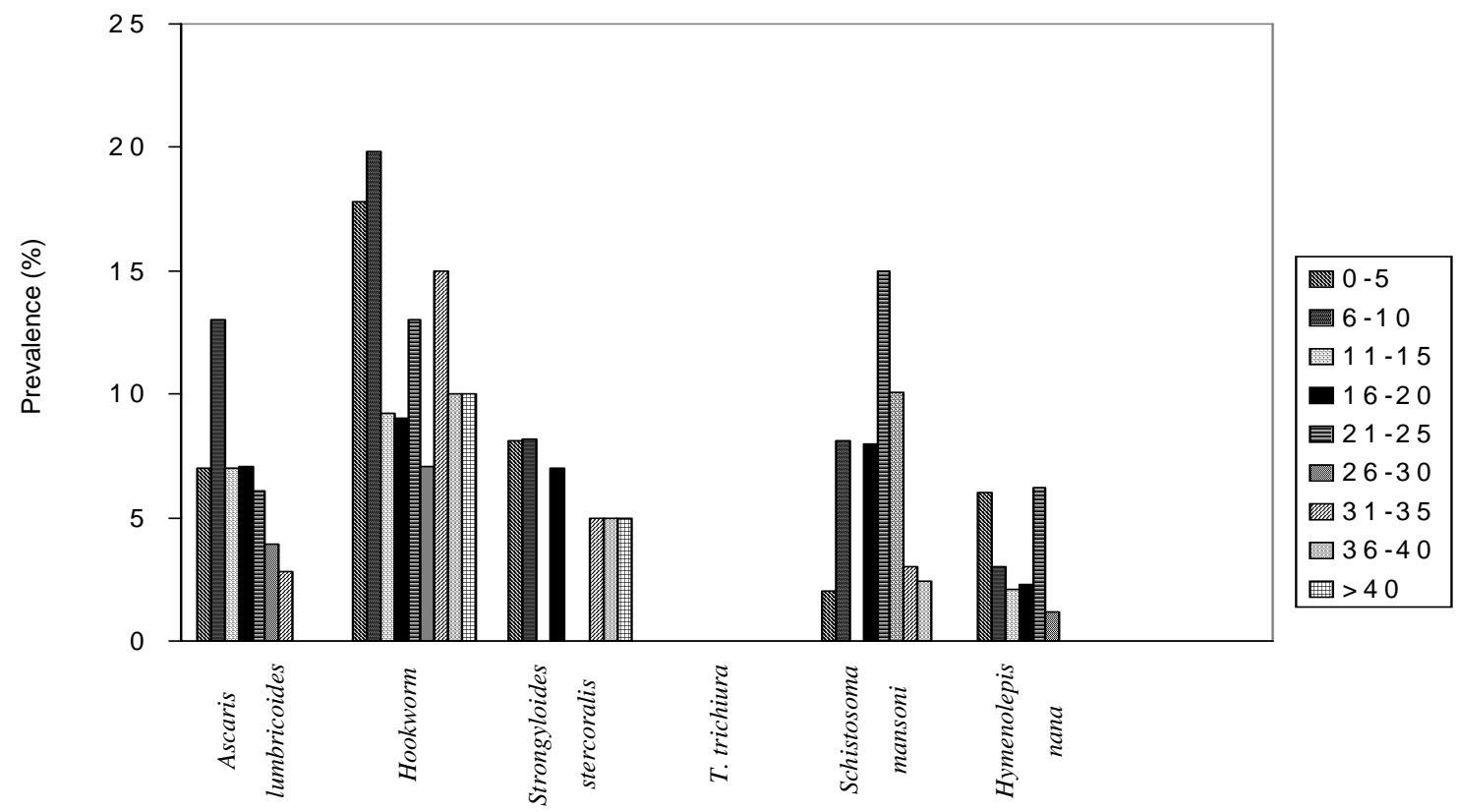

Fig 3: Prevalence of helminthes with respect to age

The present investigation shows a relatively high prevalence of intestinal helminthiasis among inhabitants of Naraguta community. In view of morbidity and medical complications of helminthiasis, free medical tests in this community and in other Nigerian rural communities are probably justifiable and should be promoted and/or sustained. Reinfection is liable to follow treatment unless there is concurrent improvement in the environmental sanitation levels of the community as proposed by Anosike et al (2004). In practice, the possibility of having either mass treatment or community-wide improvement in sanitation of the affected communities is yet to be determined in the context of the present Structural Adjustment Programme (SAP) in Nigeria. However, for protective purposes, conscientious personal cleanliness, proper sanitation and controlled good water supplies would be more useful. It is suggested that the Federal and State Environmental Sanitation Programs should provide an unprecedented opportunity to promote better personal and environmental hygiene throughout the nation. Community-wide control of helminthiasis may also accrue from the current statewide distribution of Mectizan to control onchocerciasis in several rural communities across Nigeria. Mectizan has a broad spectrum deworming effect. Operational research studies are needed to assess the impact of this on the treatment of intestinal helminths in affected communities. The attainment of these goals, coupled 
with the use of free chemotherapy, health education campaigns in rural communities and improved socioeconomic conditions will undoubtedly enhance the control of intestinal parasitism and the reduction of morbidity caused by these worms.

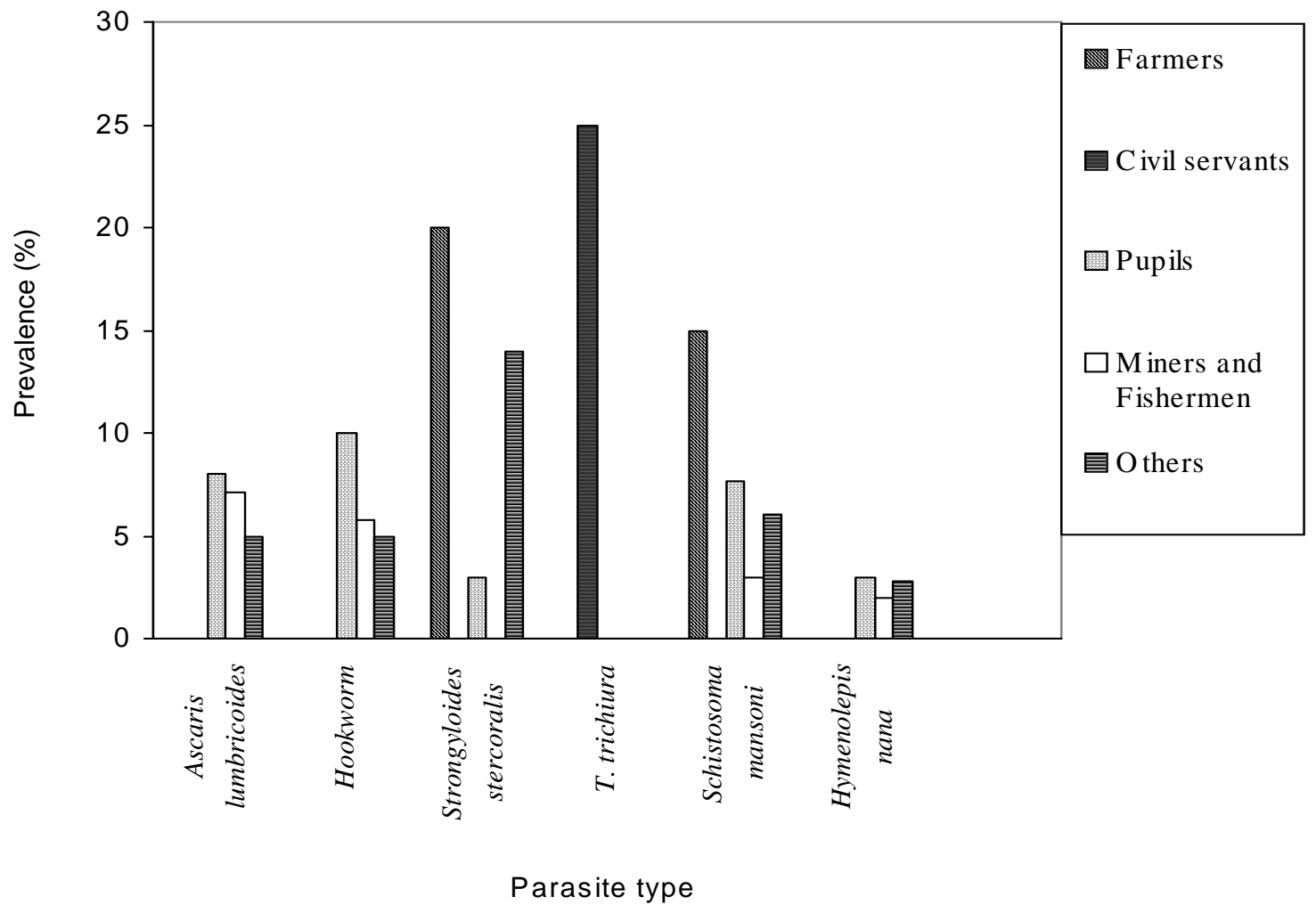

Fig 4: Prevalence of helminthes parasites with respect to occupation

Acknowledgements: We appreciate the enthusiastic assistance of Professor C.O.E. Onwuliri of the Department of Zoology, University of Jos, for criticizing the initial draft of the manuscript. We are thankful to Mrs. Clara Anosike for her help with statistical analysis.

\section{REFERENCES}

Abdullahi, I. O. And Abdulazeez, A. J. (2000). Prevalence of intestinal parasites in some human patients in Zaria. The Nigerian J. Parasitol. 21: $125-130$.

Akogun, O. B. (1990). Water demand and schistosomiasis among the Gumau people of Bauchi State, Nigeria. Trans. Roy. Soc. Trop. Med. Hyg. 84: 548 - 550.

Alo, E. B.; Anosike, J. C.; Danburan, J. B. (1993). A survey of intestinal helminths among students of post-primary institution in Adamawa State, Nigeria. Appl. Parasitol. 34: 1-7.

Anosike, J.C.; Nwoke, B.E.B; Obiukwu, C.E; Nkem, B.I; Nwoke, E.A. (2004). Epidemiological implications of Cockroaches and houseflies in the desimination of diseases in the tropical rainforest zone of south eastern Nigeria. Ann. Agric. Environ. Med. (In press).

Dada, E. O.; Adeiyongo, C. M.; Anosike, J. C.; Zaccheaus, V. O.; Okoye, S. N., Oti, E. E. (1993). Observations on the epidemiology of human taeniasis amongst the Goemai tribe of Northern Nigeria. Appl. Parasitol. 34 (4): 23 29.

Edungbola, L. D. (1988 - 90). Editorial: Parasitologists and the challenges of the decade. The Nigerian J. Parasitol. 9-11 1-2 
Gundiri, M. A. And Akogun, O. B. (2000). Gastro intestinal and urinary parasitic infections amongst School children in Rumde, Yola. The Nigerian J. Parasitol 21: 117 - 124

Ikeh, E. I.; Anosike, J. C.; Okon, E. (1992). Acanthocephalan infection in man in Northern Nigeria. J. Helminth. 66: 241- 242.

Kogi, E.; Umoh, J. U. And Vajime, C. G (1991). Intestinal parasites and gastro enteritis among patients attending the University Clinic, Samaru Zaria, Nigeria. The Nigerian J. Parasitol. 12: 77 80.

Kuka, S. A; Ajogi, I And Umoh, J. U. (2002). Helminthoses amongst primary school children in Lere L. G. A. kaduna State. The Nigerian J. parasitol. 21: 109 - 116.
Ndifon, G. T. (1991). Human Helminthiasis in 6 be Tiga Lake Basin, Kano, Nigeria. The Nigerian J. Parasitol. 12: 81- 84.

Ogbe, M. G.; Ododu, L. A. (1988-90). Gastro intestinal helminthiasis in schools in Epe Local government area, Lagos state, Nigeria. The Nigerian J. Parasitol. 9-11:95-106.

Odelowo, O. A. (1988-1990). Intestinal helminthiasis in a post secondary institution in Illorin Kwara state , Nigeria. The Nigerian .J . Parasitol. 9-11: 91-94.

Onwuliri, C.O.E.; Anosike,J.C.; Nkem,C.N.; Payne, V.K. (1993). The ecology of animal parasitic nematodes in endemic areas of Jos, Nigeria. Appl. Parasitol. (In Press).

Ukoli, F.M.A. (1990). Introduction to Parasitology in Tropical Africa-Textflow Limited, Ibadan, Nigeria. 464pp. 